\title{
New Connotation and Denotation of Global managers under the Belt \& Road Initiative -A Perspective of Individual Cross-Cultural Adaption
}

\author{
XialingWei \\ International Business School \\ Yunnan University of Finance \& Economics \\ Kunming, China \\ 286145889@qq.com
}

\author{
Ying Zhang* \\ 1. School of Management and Marketing \\ Charles Sturt University \\ Wagga Wagga, Australia \\ 2. International Business School \\ Yunnan University of Finance and Economics \\ Kunming, China \\ angie@ynufe.edu.cn
}

\begin{abstract}
The Belt \& Road economic development initiative brings out new definition, connotation, and denotation of global managers, the role of whom are particularly important in transnational management environment during the cross-border transition. This paper analyzes the adaptation of global managers in transnational corporations based on the background of the Belt\&Road Initiative. Through observing the relationship between the cultural intelligence and cross-cultural adaption, with the culture distance moderating effects, we can understand the problem what the global managers faced in the process of intercultural. As cultural intelligence using the multi-dimensional model, the adaption is also divided into social-culture adaption and psycho-culture adaption.
\end{abstract}

Keywords—global managers adaption; culture distance; culture adaption

\section{INTRODUCTION}

The Belt \& Road Initiative not only brings out economic growth, but also increases opportunities for individuals to carry out cross-border management activities. This paper mainly discusses about how a global manger is defined in or what the cultural intelligence of the global managers influence themselves' cross-cultural adaption, with the moderating effect of culture distance between cultural intelligence and cross-cultural adaption.

Earley and Ang (2003) [5] advanced that cultural intelligence were constituted by four dimensions: metacognitive, cognitive, motivational, and behavioral cultural intelligence. Searle and Ward (1990) [4] stated cross-cultural adaptation broadly describes the social-cultural sense of adaptation and psychological feelings of well-being. The relationship between the four dimensions of cultural intelligence and the two types of cross-cultural adaption will be discussed in details.

\section{LITERATURE REVIEW}

In the following sections, we review the expatriates crossculture intelligence(CQ), CQ constituted by four factors:metacognitive,cognitive,motivational and behavior CQ, and crossculture adaption are divided into two aspects: social-adaption and psycho-adaption. By analysis the relationship between social-adaption, psycho-adaption and CQ, to understand how CQ effective cross-culture adaption.

\section{A. Two dimensions of cross-cultural adaption}

Cross-cultural adaptation is a term used to signify the degree to which global managers are psychologically comfortable and familiar with different aspects of a foreign culture. Earle and Ward (1990) [4] state that; cross-cultural adaptation broadly describes, the social-cultural sense of adaptation and psychological feelings of well-being. Culturally adjusted global managers tend to be open to the host culture, and able to add new behaviors, norms, and rules to the foundation provided by home cultures. To adapt to the assignment and according to their own summed up from the social cultural adaptation and psychological culture to analyze.

\section{1) Social-cultural adaptation}

According to Ward and Kennedy (1996) [9], socialcultural adaptation refers to the ability to fit in or effectively interact with members of the host culture and host nations. it is based on cultural learning theory and highlights social behavior and practical social skills underlying attitudinal factors.

Therefore, to express the successful social-culture adaption, Black (1991) et al [13] advanced a global managers adaptation model: work adaption to express the job condition, general adaption to express the daily living condition, interaction adaption to express the condition of interact with local people where assign [13]. The global managers adaption model include the work and non-work aspects of the expatriation experience. According to Black and Mendenhall (1991) [3], Fish and Bhanugopan (2008) [10], and Molinsky (2007) [11], the notion of Adaptation is drawn from cultural learning theory and emphasizes social behavior and practical social skills underlying attitudinal and strategy factors and has been taken up in previous research on the process of an individual' $\mathrm{s}$ ability to function in a different culture.

\footnotetext{
* Corresponding author
} 


\section{2) Psycho-cultural adaptation}

Psycho-culture adaption refers to individuals' subjective well-being or satisfaction in their new cultural environments, it connected with individuals' mental adaption process, both their psychological state and potential health.

Corresponding to the psychological aspects of global manager adaptation, the concept of personal well-being has been well developed, especially in relation to work and work environment characteristics. Ward and Kennedy (1996) [3], the concept focuses on adaptation processes that reflect cultural variance in behavior, language and meaning, and it has been applied in connection to the adaptation of global manager managers. can be measured by assessing selfreported psychological symptoms and perceived distress. It is deeply rooted from Cross-cultural Psychology.

\section{B. Four factors of cultural intelligence}

Over last ten years have identified Cultural Intelligence (CQ) as a vital cross-cultural construct that determines global managers cross-cultural Adaptation process in international assignments. According to Ang (2007) et al [1], Earley and Mosakowski (2004) [6]. Global managers with higher levels of CQ are reported to be more likely to adjust at quicker rate.

The explanation for CQ was "the capacity to interact effectively with people from different cultural environment". But how can we count on effective interaction? Summarizing previous researchers opinion of CQ, what can knows that CQ draws from various disciplines including cross-cultural psychology, anthropology, sociology, and management pursued by many researchers is: Earley and Masakowski (2004) [6] illustrate that cultural intelligence resides in the body, the heart, and the head, Earley and Ang (2003) [5] further advanced that four dimensions that constitute cultural intelligence: (i)meta-cognitive, (ii)cognitive, (iii)motivational, and(iv)behavioral dimensions. it will be described in detail next.

\section{1) Meta-cognitive $C Q$}

Meta-cognition is a higher-level ability that concerns individuals' knowledge and strategy monitoring, controlling, and using the cognitive knowledge that one possesses, the important implications of meta-cognition towards crosscultural interaction and adaptation lies in the fact that metacognitive skills are fundamental to functioning in an unfamiliar cultural setting, also, it facilitates persistence and attention to details of unfamiliar verbal and nonverbal cues during cross-cultural interaction.

Planning, self-monitoring, and using of cognitive strategies are three important facet of meta-cognitive CQ. Planning means individuals must establish a goal and develop a plan to accomplish. Self-monitoring engages analysis one's own state of capability and, being aware of that state, determining a need for future practice to master a skill or manage a situation. Selfmonitoring aspect is important to achieve high levels of CQ because it helps with developing competence and avoiding the appearance of incompetence. Finally, the use of cognitive strategies in meta-cognition involves the knowledge of ones' self in relation to approaches that the global manager could use to accomplish possible strategies. The three key aspects of $\mathrm{CQ}$ in the initial stage of the cross-cultural encounter intertwine into the meta-cognitive aspect of the CQ model, through which global managers assess self and the situation when in an unfamiliar situation and then prepare behaviors and strategies that can be understood and managed.

\section{2) Cognitive $C Q$}

The second aspect of four dimensions is cognitive CQ, According to Earley and Ang (2003) [5], it refers the ability that individual gain the knowledge of a new culture that individuals may obtain and the understanding that they build up through a range of cues. Knowing oneself is not sufficient for high CQ, since awareness does not guarantee flexibility, it is important for high level CQ that supervising self-concept flexibly and possessing strong inferential capability. By using self-concept to understand new culture communication, to show the ability of cognitive CQ. A culturally intelligent person could generate an accurate mapping of the social situation to function effectively, because he or she knows 'what culture is, how cultures vary, and how culture affects behavior'.

\section{3) Motivational $C Q$}

The third aspect of four dimensions is motivation $\mathrm{CQ}$, what is supposed that individuals' willingness to face and engage the new culture and their inward desire to persevere when faced with difficult situations [7], Earley and Gibson (2002) [8] asserts that if the motivational facet of cultural intelligence is weak, Adaptation will not occur [8]. only when possess a cognitive understanding of the new culture and necessary skills can we arrive the effective cross-cultural adaption.

But motivation is not enough, the ultimate destination is participate in the culture interaction, many theories help to explanation the global manager's motivational constitution and the conceptualization of motivational CQ facet [2].

According to Earley and Ang (2003) [5], there exist three components of motivational CQ: (i) maintenance of norms and values, (ii) self-efficacy, (iii)goal-setting.

The first, maintenance of norms and values illustrate that people with high national identity with respect to their potentially negative behavior in foreign business locations and hence such people with high national identity and strong tendency to maintain familiarity being less appropriate for expatriating roles. The second, a successful intercultural interaction is based on a person's sense of efficacy for social discourse in a novel setting. Individuals who doubt their own abilities to understand and interact in new cultures are liable to "disengage after experiencing early failures" [8]. Third, goalsetting provides purpose, direction, a sense of achievement, and feedback concerning successful accomplishment of tasks and interaction.

\section{4) Behavior $C Q$}

The last aspect of four dimensional model of $\mathrm{CQ}$ is behavior CQ. Earley and Ang (2003) [5] explain the behavior $\mathrm{CQ}$ as the ability "to generate the behaviors needed to reflect cognition and motivation". In other words, possessing proper 
meta-cognitive, cognitive, and motivational elements does not necessarily ensure behavioral cultural intelligence, and behaviors that people enact in a new cultural environment do not always reflect meta-cognition, cognition and motivation which are not perceivable. Behavioral cultural intelligence is the only observable aspect of CQ to the interlocutor. So Those who with high levels of behavioral CQ are likely to be capable of exerting situation appropriate behaviors based on their broad range of verbal and nonverbal capabilities, such as presenting culturally appropriate words, tone, gestures, facial expressions and body language.

\section{Culture distance}

Cultural distance emerged as complex measure and novel metaphor of culture and distance. The cultural distance construct has been examined and applied to a variety of research questions from corporate performance [13].

Different culture have different customs, it is "culture gap", when managers into another country, what exhibit in front of them is the sources of fiction between home culture and host culture, the gap may destroy the managers' work and bring great damage. Actually, national culture plays a more important role than enterprise culture in explicate the aspect of workplace conformity. Therefore, culture distance have a significant meaning to global managers' living and work condition in another culture.

\section{THEORY DEVELOPMENT}

\section{A. Meta-cognitive Cultural Intelligence and Social-cultural Adaptation}

Meta-cognition is relevant to cultural conscious and awareness, and is thus potentially central to the ability to question cultural assumptions, consisting of planning, selfmonitoring, and use of cognitive strategies that are exploited to acquire and generate coping strategies[1]. Black (1991) et al [13], originally noted that; global managers' social-cultural Adaptation consists of three dimensions: 1) work, 2) interaction, and 3) general.

Therefore, it is naturally expected that those expatiates who with higher level of meta-cognitive CQ would be more easy social-adaption and could be better adjust to both work and non-work environments in the host country. However, greater levels of meta-cognitive CQ may not readily translate into greater social-cultural adaptation, Good planning, selfmonitoring, recognizing cognitive strategies and knowing how to behave does not necessarily ensure that proper actions can be or indeed will be carried out under new cultural circumstances. According to Earley [8], incorporate global managers' motivation or their willingness to reformulate their self-concept and give up pre-determined conceptualizations of how and why they function as they do. In 1993, a researcher study on overseas global managers shows that cognitive training failed to significantly improve cultural Adaptation. Low motivation of global managers with high level metacognitive abilities may still hinder the Adaptation process. Thus, this paper postulates that:
P1: Higher levels of meta-cognitive CQ are not a significant predictor of social-cultural.

\section{B. Meta-cognitive Cultural Intelligence and Psycho-cultural Adaptation}

Psycho-cultural adaptation refers to manager' behavior and mental adaptation processes, the process associate with expatiate individuals' personal well-being, such as their emotional state, their cognitive perceptions and their personal characteristic variables.

Cross-border assignments present substantial personal challenges for global managers because global managers may encounter various cultural and instrumental barriers in different work and life environments which may accumulate episodes of psychological stress and lead to an unstable psychological state resulting in maladaptation. Conversely, maladaptation may in turn cause cognitive fatigue and diminish the energy and effort required for effective performance. Hence, individuals with higher level of metacognitive capabilities are likely to be those that have a sound overall understanding of themselves, likely to be better able to adopt cognitive strategies to adjust mental models and to generate coping strategies against psychological stress and unstable psychological state, which can contribute to quick and smooth psycho-cultural Adaptation processes. Hence, higher levels of meta-cognitive cultural intelligence may not necessarily translate into social-cultural adaptation actions and behaviors, but will greatly assist in reducing mental stress and thereby benefit psycho-cultural Adaptation processes. Therefore, it is expected that:

P2: Higher levels of meta-cognitive CQ will be positively associated with better psycho-cultural Adaptation.

\section{Cognitive Cultural Intelligence and Social-cultural Adaptation}

According to Ang (2004\& 2007) et. Al [1][12] , cognitive CQ reflects knowledge of the norms, values and conventions in different cultures obtained from experience and training, including both the universal and culture-specific knowledge and knowledge structures. Social adaption refers to the ability of functional well in the new culture, which including i) work, ii) general living conditions, and iii) host-country national interactions[3]. Individuals with higher culture knowledge possess higher level of social-culture adaption, so, global managers will need to adjust their pre-existing management skills and behaviors to acknowledge new cultural rules and values in order to perform well in a new cultural environment,.

Nevertheless, and as first mentioned above, cognitive capabilities do not necessarily result in effective work, and non-work Adaptation actions and behaviors. A study on overseas global managers shows that cognitive training failed to significantly improve cultural adaptation, Earley and Peterson (2004) [7] also demonstrated the fact that, "awareness does not guarantee flexibility". In addition, Ang (2004) et al [15] found that cognitive cultural intelligence was not related to cross-cultural adaptation. Previous findings seem to show that cognitive abilities are not necessarily associated with better psychological adaptation to a new culture. Secondly, successful social-cultural Adaptation may 
not contribute to the knowledge base and improve cognitive CQ levels as much as stumbled or failed social-cultural Adaptation would do. Early failures and previous failed experiences in the Adaptation process make significant contributions to global managers' knowledge pool towards target cultures and thereby their cognitive CQ is likely to be enhanced. That is, cognitive cultural intelligence and socialcultural Adaptation are not positively related. Therefore, an individual high on cognitive $\mathrm{CQ}$, does not necessarily experience better social-cultural Adaptation:

P3: Cognitive CQ is not a significant predictor of socialcultural Adaptation.

\section{Cognitive Cultural Intelligence and Psycho-cultural Adaptation}

Cognitive CQ is is concerned with the cognitive aspects that involve gathering data about new cultures, comprehending the similarities and differences between home and host cultures, and functioning effectively in a new culture. According to Selmer (1999) [4], psycho-cultural adaptation focuses on effective factors that are problem-related and environmentally induced.

Previous research have suggested that greater knowledge of the host culture could reduce the level of anxiety and uncertainty towards the new environment, thus facilitating the adaptation process. However, unknown environment is likely to increase the psycho-cultural stress of global managers. Hence, a sound cross-cultural knowledge base is likely to help in reducing global manager stress and strain. Cognitive abilities should therefore contribute to a reduction in stress and enhance psychological Adaptation to a new culture. Thus, it is expected that:

P4:Higher levels of cognitive CQ are positively related to psycho-cultural Adaptation.

\section{E. Motivational Cultural Intelligence and Social-cultural Adaptation}

As previously mentioned that motivational CQ refers to individual's willingness to encounter and engage the new culture and their inward desire to persevere when faced with difficult situations. Motivation has been considered a vital aspect of cross-cultural adaptation. Earley (2002) [8] asserts that if the motivational facet of cultural intelligence is weak, cross-cultural adaptation will not come about, there three components constitute motivational CQ: maintenance of norms and values, self-efficacy, and goal-setting.

Those managers who having a strong sense of self-efficacy contributes positively to problem-solving and strategic approach when facing obstacles. However, a strong sense of efficacy alone is insufficient for high level motivational CQ because individual behaviors are influenced by their value orientations and the nature and type of goals they set, so, those people who will not be motivated to change their behavior if they with high value orientation to "National Identity" and strong aspiration and tendency to keep the norms and values of home country, therefore, the motivation of high National Identity are considered negatively related to higher levels of $\mathrm{CQ}$ and adaption. On the other hand, Earley and Petersen
(2004) [7]support that, "Human activities by their very nature are goal directed and purposeful". A motivated purposeful person is more likely to benefit from having a strong sense of direction, having guidance towards adaptation strategies, and therefore is likely to be more committed to adjusting to and persevering with a new culture when experiencing assignment difficulties and confusion. Actually, the later research result also consistent with previous findings, indicating that the greater the level of motivational CQ, the greater social-cultural Adaptation is likely to be. Based on the foregoing discussion, the following proposition is offered:

P5: Higher levels of motivational CQ are positively associated with social-cultural Adaptation.

\section{F. Motivational Cultural Intelligence and Psycho-cultural Adaptation}

Motivational cultural intelligence reflects the intrinsic interest to involve others, or the inward desire to adjust to new cultures, and the self-efficacy to function successfully in culturally heterogeneous environments. Earley and Ang (2003) [5]also suggest that it involves self-efficacy awareness and goal-setting attributes, including the intrinsic drive to be involved in cross-cultural interactions, and the inward desire to persevere when faced with difficult situations. On the other hand, psycho-cultural adaptation concerns personal well-being in the new environment, and is manifested in feelings of mental satisfaction in new cultures.

Self-efficacy refers to a judgment of one's ability to complete a certain level of performance, a critical component of what Earley and Ang (2003) [5] call "motivational cultural intelligence". Global managers with clear "quality of life awareness" and "host business and cultural awareness" displayed a higher level of "personal well-being", and thereby more likely to fit the cross-border manager role. Conversely, those displaying low efficacy may be more likely to experience an unstable psychological state and possibly even depression, which may cause threats to one's health, and / or wanting to escape from the intercultural situation, this situation can not be positive to well cross-cultural adaption, thus enhance the standpoint that self-efficacy facilitate with personal well-being, and appropriate goals are a requirement for positive self-evaluation, self-evaluation is indispensable for achieving the purpose and producing the emotional that are necessary for incentive action. Therefore, Global managers who possess higher levels of motivation to explore new cultures, who are highly efficacious in their cross-cultural interactions, and who have clear aims and goals seem more likely then, to experience better psycho-cultural adaptation . Hence, it is proposed that:

P6: Higher levels of motivational CQ are positively associated with better psycho-cultural Adaptation.

\section{G. Behavioral Cultural Intelligence and Social-cultural Adaptation}

Behavior CQ refers to the capability to generate the behaviors needed to reflect cognition and motivation. Individuals need to ensure "a well-developed repertoire of behaviors", from the election range that Earley (2002) [8]offered, from which choose the appropriate behavior and 
exert these behavior with ease and comfortable. As socialcultural Adaptation represents an individual's sense of "fitting in" to work and non-work situations, those who are sufficiently flexible to adapt their verbal and their nonverbal behaviors to new cultural circumstances, are more likely to have better self-presentation. This then, would lead to good impression and less culture conflict, and ultimately, it will trend to social-culture adaption, thus, this paper proposition that:

P7: Higher levels of behavioral cultural intelligence are positively related with social-cultural Adaptation.

\section{H. Behavioral Cultural Intelligence and Psycho-cultural Adaptation}

Behavior CQ is the capacity and capability of individuals to acquire behavioral repertoires appropriate to new cultures and to exhibit appropriate verbal and nonverbal actions in culturally diverse situations. Ward and Kennedy (1996) [9]point to a close association between psycho-cultural adaptation concerns regarding the well-being of global managers; The two studies by Ang (2004) et al [12] and Ang (2007) et al [1] also found that the behavioral dimension of CQ were positively associated with personal well-being, since flexibility plays an important role in coping with actual experiences in culturally diverse environments. The adaptive nature of high CQ global managers' behavioral (behavioral CQ) therefore was tested and found to be positively associated with better cultural adaptation.

However, it is worthwhile to point out1 that higher levels of behavioral CQ may not means better psycho-cultural adaptation, first of all, positive relationship between behavioral cultural intelligence and psycho-cultural adaptation may fail to prove itself when the global manager employ mimicry excessively rather than exerting true adaptive behaviors, that means, imitate work could suggest imitate others' behavior effectively, but this can not always bring the satisfaction. In certain cases, imitate can not be treated as the reminder in intercultural verbal and nonverbal. Therefore, adopting the behaviors that are appropriate for a particular intercultural situation does not mean that global managers need to give up their national identity. Equally, it does not necessarily demonstrate global managers' psycho-cultural comfort. Therefore, it may be expected that:

P8: Behavioral cultural intelligence does not necessarily predict psycho-cultural adaptation.

\section{New definition, connotation, and denotation of global managers}

According to the above inference, under the Belt\&Road Initiative, the transnational corporations' economy will develop with the development of the national economy and policy. This paper gives a new definition to global managers, the global managers play an important role between the home country and the host country, they are not just a expatriate, but also an important prerequisite for the quality of cultural intelligence. As mentioned above, it is necessary to have a higher level of motivational CQ, to ensure cross-cultural adaptation occurs, and with the help of meta-cognitive CQ, cognitive CQ and behavioral CQ can the global managers do what a global managers should do: Enhance company's global scale, efficiency and competitiveness, capture and respond flexibly to local market needs, and transfer expertise across the country and integrate scarce resources and capabilities across countries.

Through the new definition of global managers, this paper give the connotation: Global managers is a new type of expatriates in response to Belt\&Road Initiative, first of all, with high level of motivational CQ, and then have the ability of functioning well with individuals' knowledge and strategy monitoring, controlling, and using the cognitive knowledge that one possesses, supervising self-concept flexibly and possessing strong inferential capability, and elaborating the appropriate behavior in new environment. For the denotation of global managers, this paper propose that the staffing to seek overseas development opportunities by enterprises, play the roles of differ in thousands, for example: some staff as researchers to open up the market, some staff as sellers to sell company products, some staff as leaders to response the oversea branch office, those whom all should be like the global managers, having a higher level of motivation CQ to ensure the cross-cultural adaptation occurs, and meta cognitive CQ, cognitive CQ and motivational CQ to promote psychocultural adaptation, motivational $\mathrm{CQ}$ and behavioral CQ to promote social-cultural adaptation, with this level of $\mathrm{CQ}$, the assignment could be successful.

\section{CONCLUSIONS}

The Belt and Road initiative will promote managers circulate in different cultures, and the result is increase trend, so in order to arrive successful intercultural adaptation, need to pay more attention to the research, such as strengthen our understanding to those who are more likely to succeed in cross-cultural management and leadership roles, so as to reduce the multinational companies' staff practice costs, and increase the interests and development and enhance the strong sense of cross-cultural business relation, also, enhance personal management ability to provide perfect occupation meaningful opportunity.

Business development and personal career development may benefit by reducing the individual differences represented by our various perspectives on cultural wisdom and the gaps that are associated with more effective cross-cultural adaptation. The importance of this research that may further help to explain the individual differences in the intercultural adaptation, and to know whether the effect is conducive to business development, promote the development of the global personal occupation managers and staff to pursue strategy and practice of human resource management professionals more specifically determine and choose the more likely to get international the global managers. Individuals can also benefit by knowing more about themselves, including cultural distance and the direction of international work, so as to address the negative factors of individual differences on specific tasks. 
To solve the problem of global managers during cross cultural adaptation, we recognize that the factors of CQ: cognitive $C Q$, cognitive $C Q$, motivation $C Q$ and behavioral $\mathrm{CQ}$, how the four factors effects psycho-culture adaptation and social-culture adaption, and according to the theoretical model of global managers to give a new definition, is the main contribution if this paper. However, there are still some limitations:i)There is no specific analysis the potential capacity of the various roles and individual differences in cross-cultural business and social environment and how the CQ effect their cross-culture adaption, ii)there is no specific data to test and prove the proposal proposed in this paper.

The theoretical propositions developed in this paper cover the four dimensions of cultural intelligence offered by Earley and Ang (2003) [5] to represent individual differences, which represent individual differences. From a theoretical perspective the proposed research that this paper has explained has the significant potential to further advance models of cross-cultural adaptation, and importantly, to expand out theoretical understanding of both the model of cultural intelligence and that of cross-cultural adaptation.

\section{ACKNOWLEDGMENT}

Funding for this research was provided by National Natural Science Foundation of China under grants 71762033. The facilitation from international collaborative program and cooperation with Charles Sturt University in Australia is gratefully acknowledged. The assistance of Dr. Eshref Trushin, Professor Mark Frost and Antony Bush and comments from an associate editor and two anonymous reviewers are also acknowledged.

\section{REFERENCE}

[1] S. Ang, L. Van Dyne, C.K.S. Koh, K.Y Ng, K.J. Templer, C. Tay, and N.A. Chandrasekar, "The measurement of cultural intelligence: Effects on cultural judgment and decision making, cultural adaptation, and task performance," Management and Organization Review, vol. 3, 2007, pp. 335-371.

[2] N. Adler, "From Boston to Beijing: Managing with a World View. Cincinnati," Ohio: South-Western College Publishing, 2002.

[3] J. Black, and M. Mendenhall, "The U-Curve Adaptation Propositions Revisited: A Review and Theoretical Framework. Journal of International Business Studies," vol. 22, 1991, pp. 225-246.

[4] W. Searle, and C. Ward, "The predication of psychological and sociocultural Adaptation during cross-cultural transitions," International Journal of Intercultural Relations, vol. 14, 1990, pp. 449-64.

[5] P.C. Earley, and S. Ang, "Cultural intelligence: Individual interactions across cultures," Palo Alto, Calif: Stanford University Press, 2003.

[6] P.C. Earley, and E. Mosakowski, "Cultural intelligence," Harvard Business Review, 2004.

[7] P.C. Earley, and R.S. Peterson, "The elusive cultural chameleon: Cultural intelligence as a new approach to intercultural training for the global managers," Academy of Management Learning and Education, vol. 3, 2004, pp. 100-115.

[8] P.C. Earley, and C.B. Gibson, "Multinational work teams: A new perspective," Hillsdale, NJ: Lawrence Erlbaum, 2002.

[9] C. Ward, and A. Kennedy, "Crossing cultures: the relationship between psychological and socio-cultural dimensions of cross-cultural Adaptation," in Pandey, J., Sinha, D, Bhawuk, D.P.S (Eds),Asian Contributions to Cross-Cultural Psychology, Sage Publications, New Delhi, 1996.

[10] A. Fish, and R. Bhanugopan, "Personal wellbeing and intracultural interaction interventions for cross-border Adaptation," Cross Cultural Management: An International Journal, vol. 15, 2008, pp. 244-263.

[11] A. Molinsky, "Cross-cultural code-switching: The psychological challenges of adapting behaviour in foreign cultural interactions," Academy of Management Review, vol. 32, 2007, pp. 622-640.

[12] S. Ang, L. Vandyne, C. Koh, and K.Y. Ng, "The measurement of cultural intelligence. Paper presented at the Academy of Management Meeting's Symposium on Cultural Intelligence in the 21st Century,' New Orleans, 2004.

[13] J.S. Black, M. Mendenhall, and G. Oddou, "Toward a comprehensive model of international Adaptation: An integration of multiple theoretical perspectives," Academy of Management Review, 16, 1991, pp. 291-317. 